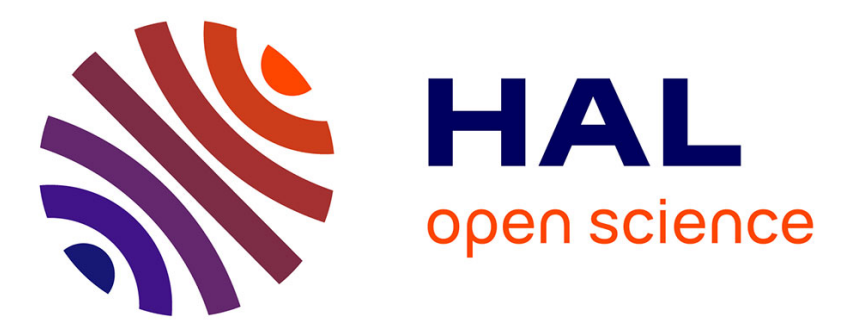

\title{
Simulation of a Doubly-Fed Induction Generator with hydro turbine for electrical energy production
}

Mamadou Baïlo Camara, Brayima Dakyo, Cristian Nichita, Georges Barakat

\section{To cite this version:}

Mamadou Baïlo Camara, Brayima Dakyo, Cristian Nichita, Georges Barakat. Simulation of a Doubly-Fed Induction Generator with hydro turbine for electrical energy production. Electric Drives Joint Symposium (ELECTROMOTION), Jul 2009, Lillie, France. pp.1-6, 10.1109/electromotion.2009.5259097 . hal-02994920

\section{HAL Id: hal-02994920 \\ https://hal.science/hal-02994920}

Submitted on 8 Nov 2020

HAL is a multi-disciplinary open access archive for the deposit and dissemination of scientific research documents, whether they are published or not. The documents may come from teaching and research institutions in France or abroad, or from public or private research centers.
L'archive ouverte pluridisciplinaire HAL, est destinée au dépôt et à la diffusion de documents scientifiques de niveau recherche, publiés ou non, émanant des établissements d'enseignement et de recherche français ou étrangers, des laboratoires publics ou privés. 
See discussions, stats, and author profiles for this publication at: https://www.researchgate.net/publication/224594799

\section{Simulation of a Doubly-Fed Induction Generator with hydro turbine for electrical energy production}

\section{Conference Paper · August 2009}

DOI: 10.1109/ELECTROMOTION.2009.5259097 · Source: IEEE XPlore

\section{CITATIONS}

24

4 authors:

M.B. Camara

Université du Havre

113 PUBLICATIONS 1,752 CITATIONS

SEE PROFILE

Cristian Nichita

Université du Havre

96 PUBLICATIONS 1,100 CITATIONS

SEE PROFILE
874

Brayima Dakyo

Université du Havre

225 PUBLICATIONS 2,873 CITATIONS

SEE PROFILE

Ghias Barakat

Damascus University

134 PUBLICATIONS 2,024 CITATIONS

SEE PROFILE

Some of the authors of this publication are also working on these related projects:

Computational Intelligence Tools Used to Solve Optimal Control Problems View project

These Intitul View project 


\title{
Simulation of a Doubly-Fed Induction Generator with Hydro Turbine for Electrical Energy Production
}

\author{
M.B. Camara, B. Dakyo, C. Nichita and G. Barakat \\ Laboratoire GREAH, UFR Sciences Techniques, Université du Havre, Le Havre, France
}

\begin{abstract}
In this paper, the authors propose a behaviour simulation of a micro power station system for electric power generation in isolated equatorial regions, e.g. Africa and South America. These remote areas have usually a good potential of hydroelectric relative to small community or activity need. They are characterized by sufficient rainfall, which leads to the steady average flow of the rivers. Despite this energy resource the electrical power generation in these regions is more often achieved by the use of diesels generators. The study proposed here deals with a hybrid electrical power station (photovoltaic and hydro turbine based on Doubly-Fed Induction Generator) and diesel generators. Two cases are considered in this paper, the first correspond to active and reactive power management when the Doubly-Fed Induction Generator is coupled to a microgrid. The second case is based on the stator voltage and frequency control when the hybrid electrical power station ensures energy to isolated electric loads.
\end{abstract}

\section{INTRODUCTION}

During these recent decades, renewable energies increasingly have give real opportunity to supply people with electrical power, taking special care to environmental requirements. However, the use of renewable energies have been for a long time marginalized in favor of other fossil energy sources, global awareness on the problems of air pollution and nuclear risks have induced recent interest. In this context, a previous study has proposed an electric power station system for the isolated equatorial regions such as Africa and South America [1]. When the electrical energy is supplied by micro-hydro power station $(\mathrm{P}<150 \mathrm{kVA})$ with variable-speed turbines, the doublyfed induction generator (DFIG) enables to optimize the power produced. This system enables also to compensate the rivers flow variability effect in acceptable proportions and guarantees a good energy quality of micro-grid. The generator control strategy based on an orientation of the stator flow ensures the control of the stator voltages and frequency whatever the turbine speed variation and the reasonable power consumption. Moreover, this system allows to coupling the DFIG with other energy sources (such the photovoltaic panels and batteries) via a common $D C$-bus for an important electrical energy supply. The originality of this system is conferred by the hybridization on DC bus of an already existing photovoltaic system as indicated in Fig. 1, which enables the magnetization of DFIG.

\section{HYDRO TURBINE MODELING}

In this study, the banki turbine is considered due to its flexibility of operation on a broad range speed and its efficiency. Moreover, considering the height average waterfalls $(1$ to $3 \mathrm{~m})$ and low velocity of the rivers $(\sim 1$ $\mathrm{m} / \mathrm{s})$, the speed of the turbine will be rather slow, but this problem can be solved by using gear box. The hydraulic power available to the turbine is given by (1).

$$
P_{h} \approx \rho \cdot g \cdot Q_{f} \cdot H
$$

This equation defines the theoretical maximum mechanical power of a waterfall. However, there are some losses due to penstock or the diversion channels. In other word, the final mechanical power is not always the theoretical mechanical power in the case of Pelton or Banki turbines. These losses are characterised by the efficiency $\eta_{c}$ of the penstock.

$$
P_{h}=\rho \cdot g \cdot Q_{f} \cdot H \cdot \eta_{c}
$$

It is interesting to define the hydro-turbine torque and the available mechanical power as function the water speed. This speed is presented in (3), where $V$ is in $(\mathrm{m} / \mathrm{s})$, $k_{v}$ a loss ratio $(\sim 0,95 \ldots 1), g$ acceleration of gravity and $H$ the fall height $(m)$ without considering pressure losses.

$$
V=k_{v} \cdot \sqrt{2 \cdot g \cdot H}
$$

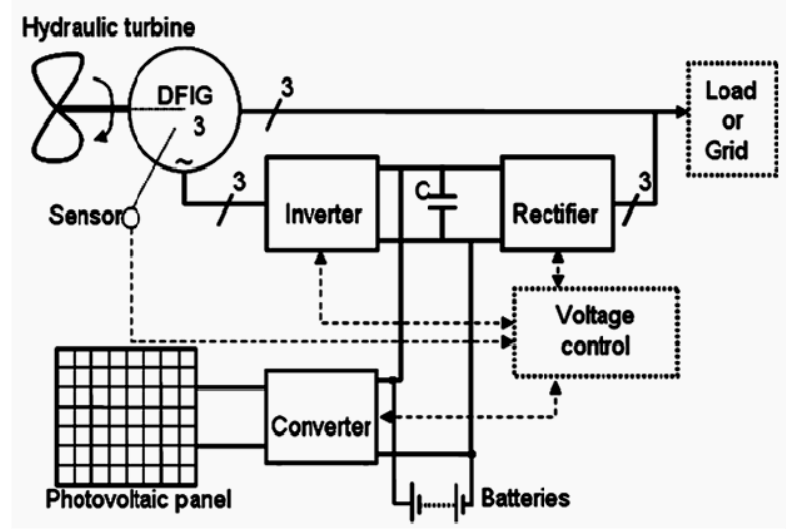

Fig.1: Doubly-fed induction generator with hydro-turbine configuration 
The mechanical power supplied by hydro-turbine can be estimated by (4), where $P_{m}$ is in $(k W), \eta$ is the global efficiency (penstock channel, gear-box, and turbine), $\rho$ present the water density $(\sim 1000 \mathrm{~kg} / \mathrm{m3})$ and the $Q_{f}$ variable defines the rivers flow $\left(\mathrm{m}^{3} / \mathrm{s}\right)$.

$P_{m}=\rho \cdot g \cdot Q_{f} \cdot H \cdot \eta$

The mechanical torque as function the river flow [1], [2], the radius and the tangential speeds is given by Euler equation (5).

$$
T_{\text {hydro }}=Q_{f} \cdot \frac{\Phi}{g} \cdot\left(r_{0} \cdot v_{t 0}-r_{1} \cdot v_{t 1}\right)
$$

Where $T_{\text {hydro }}$ is in $(\mathrm{Nm}), \varpi=\rho \cdot g$ presents the weight water per unit volume in $\left(\mathrm{N} / \mathrm{m}^{3}\right), r_{0}$ is the water filament input radius in $(m), v_{t 0}$ : water filament tangential speed in $(\mathrm{m} / \mathrm{s})$, $r_{1}$ and $v_{t 1}$ are respectively the output wheel radius in $(m)$ and tangential speed in $(\mathrm{m} / \mathrm{s})$.

From (5), the mechanical power $P_{m}$ of the turbine can be also estimated as function the hydro-turbine speed $\omega$ in $(\mathrm{rd} / \mathrm{s})$ as indicated in (6).

$$
P_{m}=T_{\text {hydro }} \cdot \omega_{m}
$$

In the Banki turbines, the actual values often differ from those calculated because of pressure losses existing in the penstock or the diversion channels resulting from $H$ parameter.

\section{DOUBLY-FED INDUCTION GENERATOR AND MICRO GRID/LOAD MODELLING}

\section{A. Doubly-Fed Induction Generator Modelling}

In the case of the energy production by hydraulic turbine, the Doubly Fed Induction Generator (DFIG) enables to optimize the produced power [3-7]. Indeed, considering the variable speeds and the rivers flows in the equatorial regions, the $D F I G$ allows compensating these variations in acceptable proportions while guaranteeing a good quality of the micro-grid. The control strategy consists in first case to providing constant voltage $V_{s}$ and frequency $f_{s}$ at stator, whatever of the speed variations and reasonable energy consumption, when the system is in isolated area. In second case, it consists to control active and reactive power when the generator is coupled to existing micro-grid [8-11].

The dynamic model of DFIG [12-15] in Park axes system $(d, q)$ is defined by (7) and (8), where $R_{s}, R_{r}, L_{s}, L_{r}$ and $M$ present the generator parameters, which are giving in Table I (Appendix).

$$
\left\{\begin{array}{l}
V_{s d}=R_{S} \cdot I_{s d}+\frac{d}{d t}\left(\Phi_{s d}\right)-\omega_{s} \cdot \Phi_{s q} \\
V_{s q}=R_{S} \cdot I_{s q}+\frac{d}{d t}\left(\Phi_{s q}\right)+\omega_{s} \cdot \Phi_{s d}
\end{array}\right.
$$

$$
\left\{\begin{array}{l}
V_{r d}=R_{r} \cdot I_{r d}+\frac{d}{d t}\left(\Phi_{r d}\right)-\omega_{r} \cdot \Phi_{r q} \\
V_{r q}=R_{r} \cdot I_{r q}+\frac{d}{d t}\left(\Phi_{r q}\right)+\omega_{r} \cdot \Phi_{r d}
\end{array}\right.
$$

The magnetic fluxes at the stator and rotor in Park axes system are respectively defined in (9).

$$
\left\{\begin{array}{l}
\Phi_{s d}=L_{s} \cdot I_{s d}+M \cdot I_{r d} \\
\Phi_{s q}=L_{s} \cdot I_{s q}+M \cdot I_{r q} \\
\Phi_{r d}=L_{r} \cdot I_{r d}+M \cdot I_{s d} \\
{ }_{r d}=L_{r q} \cdot I_{r q}+M \cdot I_{s q}
\end{array}\right.
$$

After some transformations of (7), (8) and (9) equations, the dynamic model of $D F I G$ can be presented by differential equations (10), where $A, B$ and $\sigma$ are defined below.

$$
\frac{d}{d t}\left[\begin{array}{c}
I_{s d} \\
I_{s q} \\
I_{r d} \\
I_{r q}
\end{array}\right]=[A] \cdot\left[\begin{array}{c}
I_{s d} \\
I_{s q} \\
I_{r d} \\
I_{r q}
\end{array}\right]+[B] \cdot\left[\begin{array}{c}
V_{s d} \\
V_{s q} \\
V_{r d} \\
V_{r q}
\end{array}\right]
$$

$$
\begin{aligned}
& {[A]=\left[\begin{array}{cccc}
-\frac{R_{S}}{\sigma \cdot L_{S}} & \left(\omega_{S}+\frac{(1-\sigma)}{\sigma} \cdot \omega\right) & \frac{M}{\sigma \cdot L_{S}} \cdot \frac{R_{r}}{L_{r}} & \frac{M \cdot \omega}{\sigma \cdot L_{S}} \\
-\left(\omega_{S}+\frac{(1-\sigma)}{\sigma} \cdot \omega\right) & -\frac{R_{S}}{\sigma \cdot L_{S}} & -\frac{M \cdot \omega}{\sigma \cdot L_{S}} & \frac{M}{\sigma \cdot L_{S}} \cdot \frac{R_{r}}{L_{r}} \\
\frac{M}{\sigma \cdot L_{r}} \cdot \frac{R_{S}}{L_{S}} & -\frac{M \cdot \omega}{\sigma \cdot L_{r}} & -\frac{R_{r}}{\sigma \cdot L_{r}} & \left(\omega_{S}-\frac{\omega}{\sigma}\right) \\
\frac{M \cdot \omega}{\sigma \cdot L_{r}} & \frac{M}{\sigma \cdot L_{r}} \cdot \frac{R_{S}}{L_{S}} & -\left(\omega_{S}-\frac{\omega}{\sigma}\right) & -\frac{R_{r}}{\sigma \cdot L_{r}}
\end{array}\right]} \\
& {[B]=\left[\begin{array}{cccc}
\frac{1}{\sigma \cdot L_{S}} & 0 & -\frac{(1-\sigma)}{\sigma \cdot M} & 0 \\
0 & \frac{1}{\sigma \cdot L_{S}} & 0 & -\frac{(1-\sigma)}{\sigma \cdot M} \\
-\frac{(1-\sigma)}{\sigma \cdot M} & 0 & \frac{1}{\sigma \cdot L_{r}} & 0 \\
0 & -\frac{(1-\sigma)}{\sigma \cdot M} & 0 & \frac{1}{\sigma \cdot L_{r}}
\end{array}\right],\left(1-\frac{M}{L_{S} \cdot L_{r}}\right)}
\end{aligned}
$$

In this dynamic model:

- $I_{s d}$ and $I_{s q}$ (stator currents) with rotor current $\left(I_{r d}, I_{r q}\right)$ present the state variables.

- $\quad V_{s d}$ and $V_{s q}$ correspond to stator voltage which can be obtained from micro grid or load model

- $V_{r d}$ and $V_{r q}$ correspond to system control variables (rotor voltages) which can be obtained from inverter ( $D C / A C$ converter) average model

These equations can be solved easily by using $S$-function algorithm implemented in Matlab/Simulink software.

The electromechanical equation of the system is giving in (11), where $f$ presents the coefficient of viscous friction.

$$
J_{t} \cdot \frac{d}{d t}\left(\Omega_{m}\right)=T_{m}-T_{e m}-f \cdot \Omega_{m}
$$

In this equation, the mechanical torque $T_{m}$, and electromagnetic torque $T_{e m}$ can be estimated using (12) 
and (13), where $p$ and $\Omega$ define respectively the pair of poles number and hydraulic turbines speed:

$$
\begin{aligned}
& \left\{\begin{array}{l}
\Omega_{m}=G \cdot \Omega \\
T_{m}=\frac{T_{h y d r o}}{G}
\end{array}\right. \\
& T_{e m}=p \cdot M \cdot\left(I_{s q} \cdot I_{r d}-I_{s d} \cdot I_{r q}\right)
\end{aligned}
$$

The shaft system provides a coupling between the turbine rotor and generator rotor. It is necessary that the shaft dynamics should be included in simulation models, even in variable speed turbines because shaft oscillations and power fluctuations. Alternatively, the two masses can be considered [16], referring the inertias to the high speed shaft as in (14), where $J_{t}$ is the global inertia in $\mathrm{kgm}^{2}$ and $G$ is the gear-box ratio

$$
J_{t}=\frac{J_{\text {turb }}}{G^{2}}+J_{D F I G}
$$

\section{B. Micro Grid/Load Modelling}

The main goal of this section consists to establish a global model which enables to deduce the grid and load models. To establish these models, the balanced three phase system is considered. The grid/load coupling strategy is presented in Fig.2. When the stator of the $D F I G$ is coupled to balanced three phase load, $E_{d}$ and $E_{q}$ are zero. When the DFIG is coupled to an existing microgrid, then $E_{d}$ and $E_{q}$ can be obtained by using Park transformation on following fundamental equations.

$$
\left\{\begin{array}{l}
e_{1}=E \cdot \sqrt{2} \cdot \sin \left(\omega_{s} \cdot t\right) \\
e_{2}=E \cdot \sqrt{2} \cdot \sin \left(\omega_{s} \cdot t-\frac{2 \cdot \pi}{3}\right) \\
e_{2}=E \cdot \sqrt{2} \cdot \sin \left(\omega_{s} \cdot t+\frac{2 \cdot \pi}{3}\right)
\end{array}\right.
$$

Two phases resulting model is presented in (16), where $R$ and $L$ correspond respectively to load or grid resistance and inductance

$$
\left\{\begin{array}{l}
V_{s d}=-R \cdot I_{s d}-L \cdot \frac{d}{d t}\left(I_{s d}\right)+\omega_{s} \cdot L \cdot I_{s q}-E_{d} \\
V_{s q}=-R \cdot I_{s q}-L \cdot \frac{d}{d t}\left(I_{s q}\right)-\omega_{s} \cdot L \cdot I_{s d}-E_{q}
\end{array}\right.
$$

To implement this equation in Matlab/Simulink (using transfer function), it is necessary to transform (16) as shown equations (17) and (18). The implementation of these equations is showing in Fig.3, where $E_{\max }=2^{1 / 2} . E$.

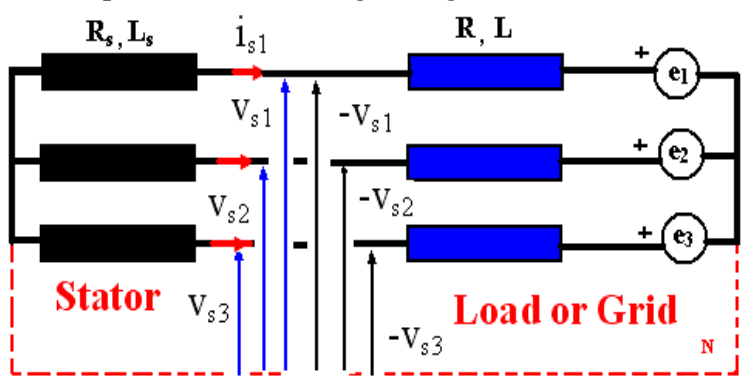

Fig.2: Stator and grid coupling strategy

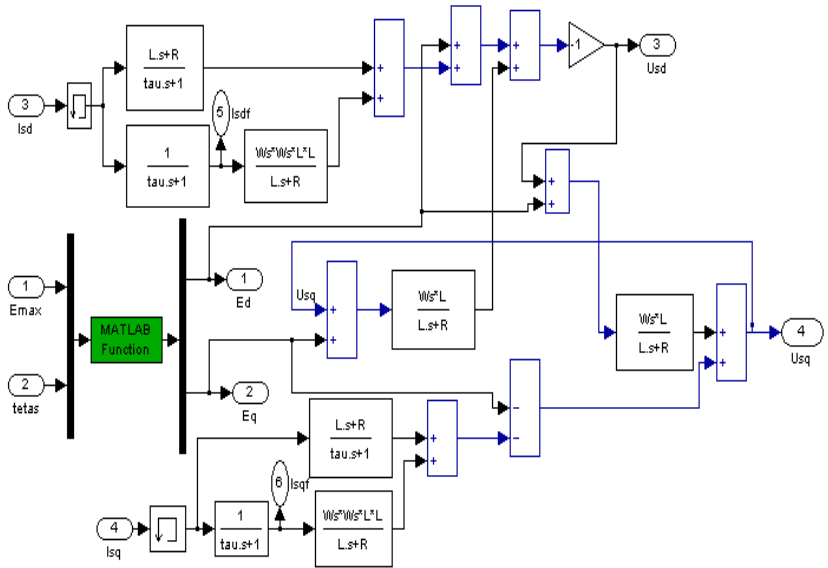

Fig.3: $V_{s d}$ and $V_{s q}$ implementation strategy with tetas $=\boldsymbol{\omega}_{\boldsymbol{s}} . \boldsymbol{t}$

$V_{s q}=\frac{\omega \cdot L \cdot\left(V_{s q}+E_{d}\right)}{R+L \cdot s}-E_{q}-\left(\frac{\omega_{s}^{2} \cdot L^{2}}{(R+L \cdot s) \cdot(1+\tau \cdot s)}+\frac{R+L \cdot s}{1+\tau \cdot s}\right) \cdot I_{s q}$

$V_{s d}=-\frac{\omega \cdot L \cdot\left(V_{s q}+E_{q}\right)}{R+L \cdot s}-E_{d}-\left(\frac{\omega_{s}^{2} \cdot L^{2}}{(R+L \cdot s) \cdot(1+\tau \cdot s)}+\frac{R+L \cdot s}{1+\tau \cdot s}\right) \cdot I_{s q}$

\section{DOUBLY-FED INDUCTION GENERATOR CONTROL STRATEGY}

The system control strategy includes two states. The first correspond to active and reactive power control when the DFIG is coupled to existing grid. The second strategy deals stator voltage control when the generator ensures electrical energy to isolated electric loads.

\section{A. Active and reactive power control strategy}

For active and reactive power control strategy simplifying, the reference frame must be choose where equation (7) must be projected. Indeed, the majority of authors choose a reference frame related to the stator.

However, this choice is not best in this application, i.e. the parameters must to be controlled are in stator $(P, Q)$, the choice of an axes system shifted $90^{\circ}$ behind on the vector of stator voltage $\left(V_{s d}=0\right.$ and $\left.V_{s q}=V_{s}\right)$ is much more advantageous. It allows connecting the axes system directly to the frequency of the micro-grid and

Fig.4 illustrates this choice. The active and reactive power control strategy obtained from this assumption is presented in Fig.5, where the decoupling terms $V_{r d}, V_{r q}$, are as function the rotor currents and stator flux as indicated in (19).

$$
\left\{\begin{array}{l}
V_{r d}^{\prime} \approx\left(\omega_{s}-\omega\right) \cdot \sigma \cdot L_{r} \cdot I_{r q} \\
\Phi_{s d} \approx \frac{V_{s q}-R_{s} \cdot I_{s q}}{\omega_{s}} \\
V_{r q}^{\prime} \approx\left(\omega_{s}-\omega\right) \cdot \sigma \cdot L_{r} \cdot I_{r d}+\left(\omega_{s}-\omega\right) \cdot \frac{M}{L_{S}} \cdot \Phi_{s d}
\end{array}\right.
$$


In the $d-q$ reference frame, the active and reactive powers [17-19] absorbed from the grid can be obtained from following equations.

$$
\left\{\begin{array}{l}
P=V_{s d} \cdot I_{s d}+V_{s q} \cdot I_{s q} \\
Q=V_{s q} \cdot I_{s d}-V_{s d} \cdot I_{s q}
\end{array}\right.
$$

Choosing $d$-axis as the reference frame along the statorflux arrangement and assuming the stator resistance is negligible, $V_{s d}$ is zero, and, since the amplitude of the supply voltage is constant, $V_{s q}$ is constant. Therefore, the reactive and active power will be proportional to $I_{r d}$ and $I_{r q}$, respectively as indicated in (21).

$$
\left\{\begin{array}{l}
P \approx-\frac{M}{L_{s}} \cdot V_{s q} \cdot I_{r q} \\
Q \approx V_{s q} \cdot\left(\frac{\Phi_{s d}}{L_{s}}-\frac{M}{L_{s}} \cdot I_{r d}\right)
\end{array}\right.
$$

The stator active power reference is estimated from mechanical torque and this estimation method is illustrated by (22), where, $k$ is constant coefficient with a maximum value of $\omega_{s}=314 \mathrm{rd} / \mathrm{s}$.

$$
P_{r e f} \approx k \cdot T_{m}
$$

\section{B. Voltage control strategy}

If the DFIG is used for autonomous grid, the control strategy must be based on stator voltage and frequency. This control is same to that of power control strategy and can be obtained from Fig.5, i.e. by replacing $Q_{\text {ref }}$ by $V_{\text {sqref }}$ and $P_{\text {ref }}$ by $V_{\text {sdref }}$ respectively and the remainder terms presented in Fig.5 are identical that to voltage control strategy.

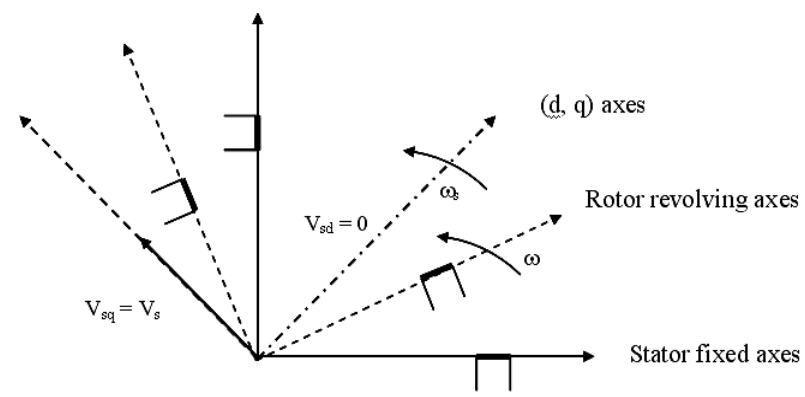

Fig. 4 : Reference frame choice $(\mathrm{d}, \mathrm{q})$

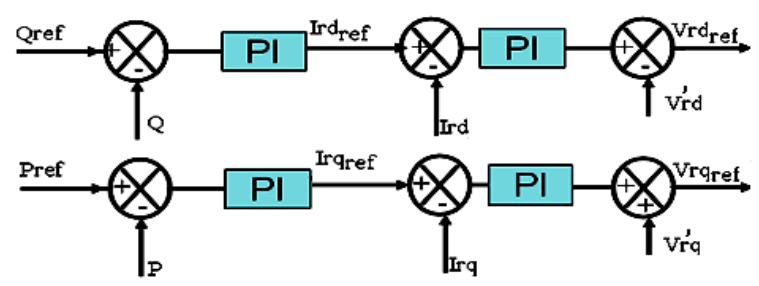

Fig.5: Active and reactive power control strategy

\section{Simulation Results}

The main goal of this section consists to system dynamic performance evaluation with classical $P I$ controller [20] and some simulation results presented in this paper are obtained in following conditions:
- The hydro-turbine speed reference $\left(w_{\text {mref }}\right)$ is estimated as function the river flow $\left(Q_{f}\right)$

- The stator reactive power reference $\left(Q_{r e f}\right)$ is respectively fixed at (2,0 and 1) $k V A R$.

- The active power reference is estimated from equation (22), with $k=3.14 \mathrm{rd} / \mathrm{s}$.

By convention, the sign of power (active and reactive) is assumed negative for the supplied power and positive in contrary conditions (consumed power). For divergence problems, a lower sampling period $\left(1 e^{-8} s\right)$ is used for system simulations.

\section{A. Active and reactive power control result}

To illustrate the performance of power control strategy, three closed loops are used. The first is based on mechanical speed control as function the river flow. The second and third are respectively focused on active and reactive powers control.

The simulation result corresponding to first loop is presented in Fig.6. These curves show the control strategy is satisfactory except the start condition when the mechanical speed loop have not adequate time to react.

The active and reactive powers measured at the stator of the DFIG when the generator is coupled to micro-grid are respectively shown in Fig.7 and Fig.8; these results allow to concluding the used control strategy is very interesting.
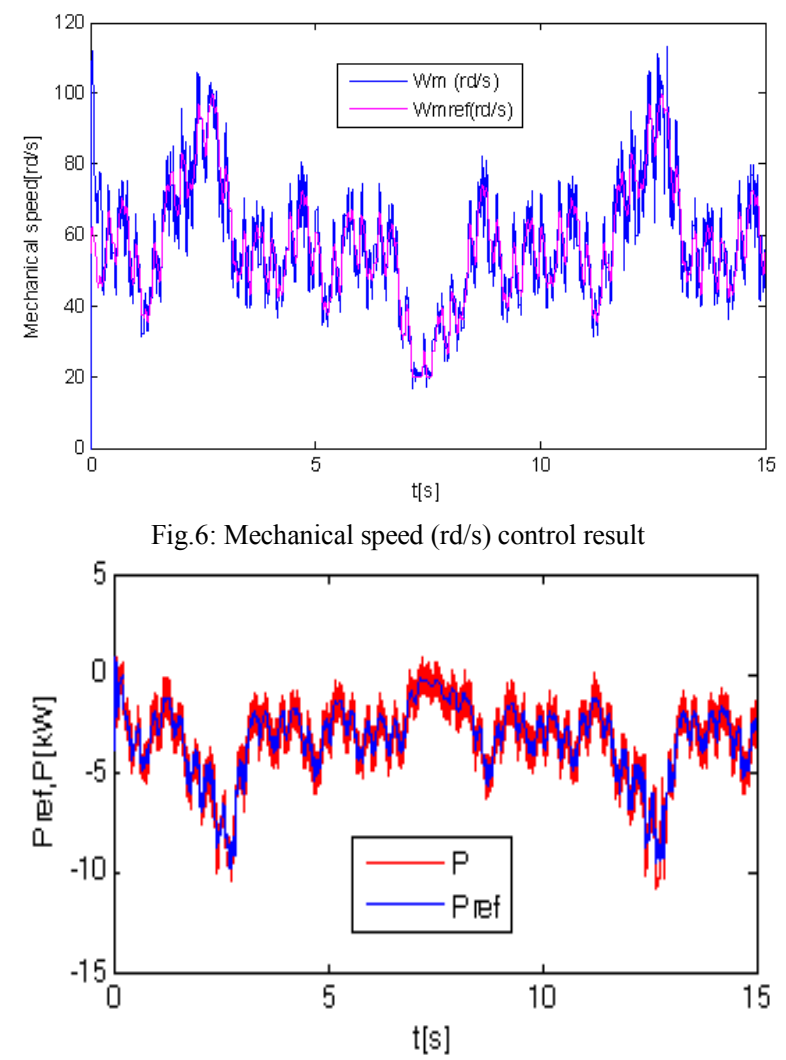

Fig.7: Stator active power control result

The measured powers compared to the reference powers estimated shows that this control strategy takes into account the river flow $\left(Q_{f}\right)$ variation. But some ripples appear in reactive power when the mechanical speed exceeds $80 \mathrm{rad} / \mathrm{s}$. 


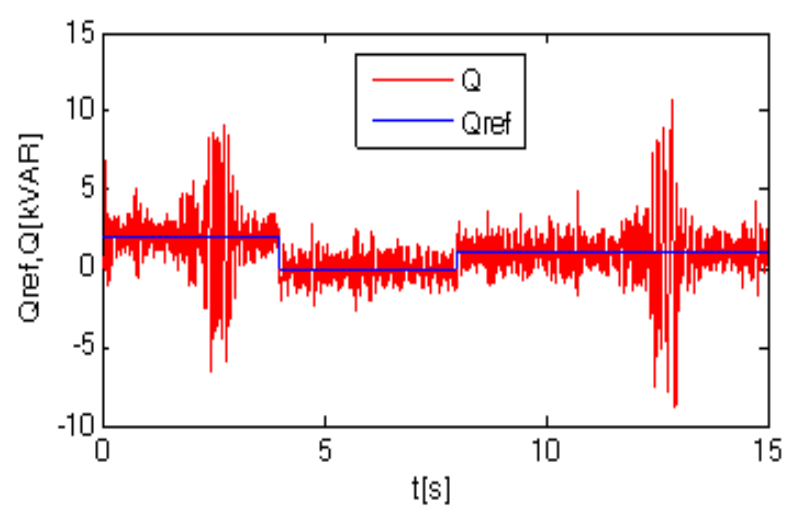

Fig.8: Stator reactive power control result

\section{B. Stator voltage and frequency control result}

For stator voltage and frequency control performance evaluation, two closed loops are used. The simulation results presented in Fig.9 to Fig.12 correspond to stator frequency and voltage $\left(V_{s d}, V_{s q}\right)$ control results when the $D F I G$ is in isolated area (no micro-grid). Fig.9 shows the stator frequency $\left(f_{s}\right)$ compared to synchronism frequency $\left(f_{s n}\right)$. That of shift and the rotor frequencies, they are respectively presented in Fig.10 and Fig.11. The stator voltages control result for two phase model $(d, q)$ of the $D F I G$ is showed in Fig.12. These results enable to observe the voltage and the frequency control is satisfactory.

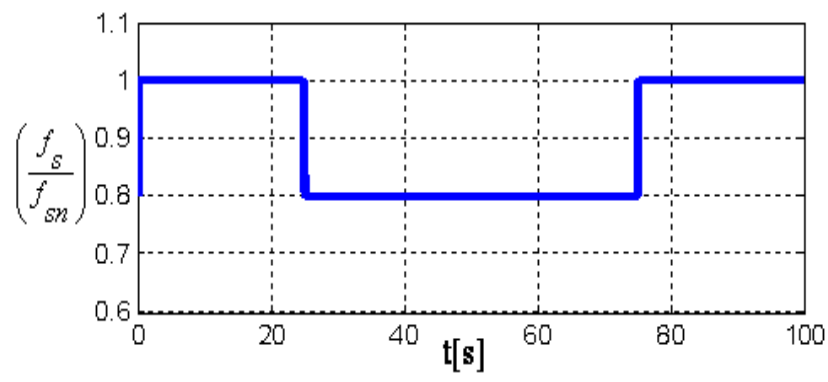

Fig.9: DFIG stator frequency control result

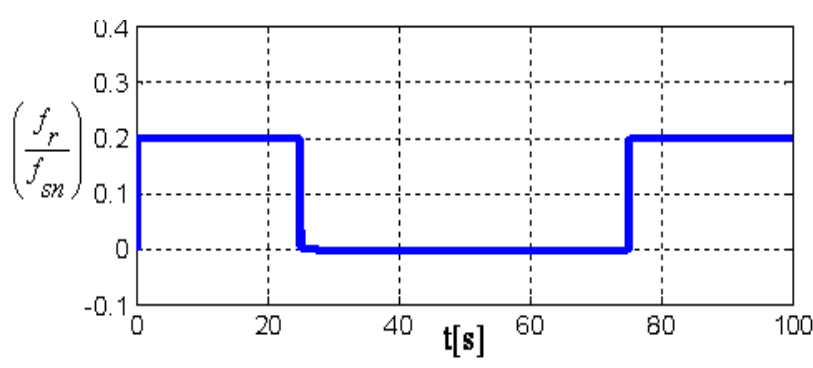

Fig.10: DFIG rotor frequency

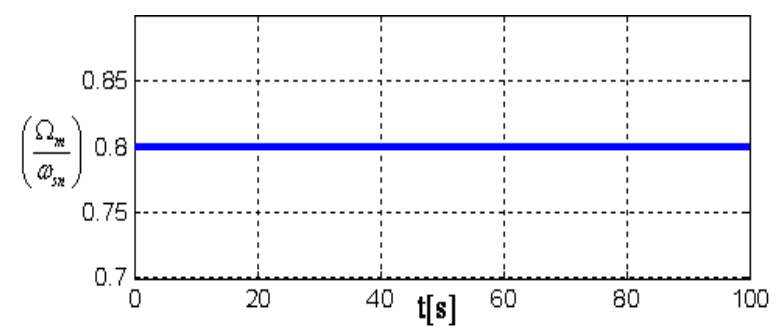

Fig.11: DFIG mechanical speed in p.u

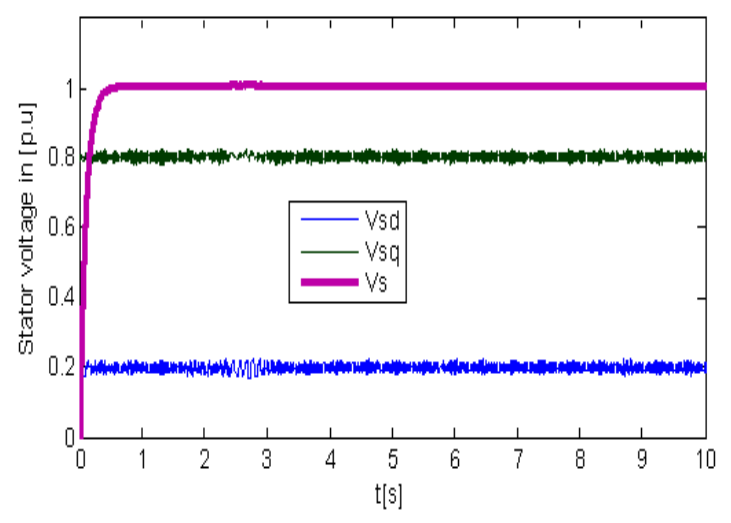

Fig.12: Stator voltage $\left(V_{s d}, V_{s q}\right)$ measured on $d-q$ axis, with

$$
V_{s}=\sqrt{V_{s d}^{2}+V_{s q}^{2}}
$$

\section{CONCLUSION}

Due to the rivers speeds and flows variations in the equatorial areas, a Doubly Fed Induction Generator $(D F I G)$, presents an original solution for compensate the variability of the primary source in acceptable proportions, thus guarantees a good quality of the produced energy. The magnetization energy of the Doubly Fed Induction Generator is ensured by photovoltaic cells through a $D C$ bus. The simulations results presented in this paper show that the proposed system is interesting for micro hydro power station applications.

The future developments will be based on the various control devices and hybridization possibilities with other electrical energy systems production with strong variability in the isolated equatorial areas. The control strategy of voltage and power (active and reactive) are satisfactory as shown by simulations results. These controls strategy will be implemented in reduced experimental test bench which is at the moment in design state.

\section{APPENDIX}

TABLE I. PARAMETERS OF DOUBLY FED INDUCTION GENERATOR

\begin{tabular}{lc}
\hline \hline \multicolumn{1}{c}{ Name } & DFIG \\
Stator voltage $\left(V_{s n}\right)$ & $220 \mathrm{~V}$ \\
Base frequency & $50 \mathrm{~Hz}$ \\
Stator resistance $\left(R_{s}\right)$ & $1.75 \Omega$ \\
Rotor resistance $\left(R_{r}\right)$ & $1.68 \Omega$ \\
Rotor leakage inductance $\left(L_{r}\right)$ & $104 \mathrm{mH}$ \\
Mutual inductance $(M)$ & $165 \mathrm{mH}$ \\
Number of pole pair $(p)$ & 2 \\
Stator leakage inductance $\left(L_{s}\right)$ & $295 \mathrm{mH}$ \\
Load resistance $(R)$ & $1 \Omega$ \\
Load inductance $(L)$ & $310 \mathrm{mH}$ \\
Gear box $(G)$ & 23 \\
Viscous friction coefficient $(f)$ & 0.0027 N.m.s.rd \\
\hline \hline
\end{tabular}




\section{REFERENCES}

[1] D. Ramuz, M. Camara, M. Sebeloue, O.Tamarin, F. Roubaud, H. Clergeot, J-M. Kauffmann, "Modelling and Simulation of a Doubly Fed Induction Generator in stand alone Variable Speed Hydro Turbine" EPE 2005, Dresden

[2] Sylvain, "Petites centrales hydrauliques", Technique de l'ingénieur, traité Génie électrique, D3930, pp : 1-18

[3] S. Muller, M. Deicke, R.W. De Doncker : "Doubly-Fed Induction Generators Systems for Wind Turbines", IEEE Industry Applications Magazine, May, June 2000

[4] B. Robyns, Y. Pankow, L. Leclercq, B. François : "Equivalent Continuous Dynamic Model of Renewable Energy Systems", 7th International Conference on Modeling and Simulation of Electric Machines, Converters and Systems : ELECTRIMACS 2002, Canada, Montreal, CD

[5] Armand Boyette and Shahrokh Saadate, Philippe Poure, "Direct and indirect control of a Doubly Fed Induction Generator wind turbine including a storage unit" IEEE, 2006, pp:2517-2522

[6] Jiahu Guo, Xu Cai and Youming Gong, "Decoupled Control of Active and Reactive Power for a Grid-connected Doubly-fed Induction Generator" DRPT2008 6-9 April 2008

[7] Denis Ramuz, Mamadou Camara, Henri Clergeot and Jean Marie Kauffmann, "Simulation of a Doubly Fed Induction Generator used in an Autonomous Variable Speed Hydro Turbine with Maximum Power Point Tracking Control", EPE-PEMC, Portoroz, Slovonia 2006, pp:1620-1624

[8] F.Poitiers, M.Machmoum, R.LeDoeuff: 'Simulation of a Wind Energy Conversion System Based on a Doubly Fed Induction Generator', EPE 2003, CD, pp1-10

[9] O.Gergaud, G.Robin, B.Multon, H.Ben Ahmed : "Energy modeling of a lead acid battery within hybrid Wind / Photovoltaic systems" : EPE 2003 - Toulouse CD-Rom

[10] Jing Zhao; Wei Zhang; Yikang He; Jiabing Hu; "Modeling and control of a wind-turbine-driven DFIG incorporating core saturation during grid voltage dips", IEEE International Conf. on Electrical Machines and Systems, ICEMS 2008. 17-20 Oct. 2008, Page(s):2438 - 2442
[11] Shuhui Li; Haskew, T.A.; "Analysis of Decoupled d-q Vector Control in DFIG Back-to-Back PWM Converter", IEEE Conf. PES 2007, 24-28 June 2007, Page(s): 1 - 7

[12] Wei Qiao; Harley, R.G.; "Improved Control of DFIG Wind Turbines for Operation with Unbalanced Network Voltages", IEEE Conf. IAS.2008, 5-9 Oct. 2008 Page(s):1 - 7

[13] Ren-jie Ye; Hui Li; Zhe Chen; Qiang Gao; "Comparison of transient behaviors of wind turbines with DFIG considering the shaft flexible models", IEEE International Conf. on Electrical Machines and Systems, ICEMS 2008. 17-20 Oct. 2008, Page(s):2585 - 2590

[14] Feng Wu; Xiao-Ping Zhang; Ping Ju; Sterling, M.J.H.; "Decentralized Nonlinear Control of Wind Turbine With Doubly Fed Induction Generator", IEEE Trans. on power systems, Volume 23, Issue 2, May 2008, Page(s):613 - 621

[15] Yu Fang; Liu Qi-hui; Zhang Jian-hua; “ Flexible Grid-connection Technique and Novel Maximum Wind Power Tracking Algorithm for Doubly-Fed Wind Power Generator", IEEE International Conf. on Industrial Electronics Society IECON 2007, 5-8 Nov. 2007, Page(s):2098 - 2103

[16] Kayikci, M.; Milanovic, J.V.; "Assessing Transient Response of DFIG-Based Wind Plants-The Influence of Model Simplifications and Parameters", IEEE Trans. on power systems, Volume 23, Issue 2, May 2008, Page(s):545 - 554

[17] Lie Xu; Yi Wang; "Dynamic Modeling and Control of DFIGBased Wind Turbines Under Unbalanced Network Conditions", IEEE Trans. on power systems, Volume 22, Issue1, Feb. 2007 Page(s):314 - 323

[18] Lie Xu; "Coordinated Control of DFIG's Rotor and Grid Side Converters During Network Unbalance", IEEE Trans. on Power Electronics, Volume 23, Issue 3, May 2008 Page(s):1041 - 1049

[19] Hu, J.; He, Y.; Xu, L.; Williams, B.W.; "Improved Control of DFIG Systems During Network Unbalance Using PI-R Current Regulators" IEEE Trans. on Industrial Electronics, Volume 56, Issue 2, Feb. 2009, Page(s):439 - 45

[20] Camara M.B., Gualous H., Gustin F. and Berthon A., "Design and New Control of DC/DC Converters to share energy between Supercapacitors and Batteries in Hybrid Vehicle", IEEE Trans. on Vehicular Technology Vol 57 sept. 2008 